\title{
Simple Cyst of Kidney
}

National Cancer Institute

\section{Source}

National Cancer Institute. Simple Cyst of Kidney. NCI Thesaurus. Code C123173.

A homogenous cyst located in the kidney. 